\title{
Novel Insights into the Genetic Controls of Primitive and Definitive Hematopoiesis from Zebrafish Models
}

\author{
Raman Sood and Paul Liu \\ Oncogenesis and Development Section, National Human Genome Research Institute, National Institutes of Health, Bethesda, \\ MD 20892, USA \\ Correspondence should be addressed to Paul Liu, pliu@nhgri.nih.gov
}

Received 28 March 2012; Revised 20 May 2012; Accepted 8 June 2012

Academic Editor: Elspeth Payne

Copyright ( $\odot 2012$ R. Sood and P. Liu. This is an open access article distributed under the Creative Commons Attribution License, which permits unrestricted use, distribution, and reproduction in any medium, provided the original work is properly cited.

Hematopoiesis is a dynamic process where initiation and maintenance of hematopoietic stem cells, as well as their differentiation into erythroid, myeloid and lymphoid lineages, are tightly regulated by a network of transcription factors. Understanding the genetic controls of hematopoiesis is crucial as perturbations in hematopoiesis lead to diseases such as anemia, thrombocytopenia, or cancers, including leukemias and lymphomas. Animal models, particularly conventional and conditional knockout mice, have played major roles in our understanding of the genetic controls of hematopoiesis. However, knockout mice for most of the hematopoietic transcription factors are embryonic lethal, thus precluding the analysis of their roles during the transition from embryonic to adult hematopoiesis. Zebrafish are an ideal model organism to determine the function of a gene during embryonicto-adult transition of hematopoiesis since bloodless zebrafish embryos can develop normally into early larval stage by obtaining oxygen through diffusion. In this review, we discuss the current status of the ontogeny and regulation of hematopoiesis in zebrafish. By providing specific examples of zebrafish morphants and mutants, we have highlighted the contributions of the zebrafish model to our overall understanding of the roles of transcription factors in regulation of primitive and definitive hematopoiesis.

\section{Zebrafish as a Model for Hematopoiesis}

Recently, zebrafish have emerged as a powerful vertebrate model system due to their external fertilization, optically clear embryos, rapid development, availability of tools for manipulations of gene expression during development, and the ability to generate genetic mutants by random (insertional and chemical) and targeted mutagenesis [1-3]. Microinjections of antisense morpholinos, which cause transient knockdown of gene activity, and mRNA allows for analysis of the effects of loss and gain of function of specific genes during development [4]. Whole-mount in situ hybridization (WISH) is a powerful technique to analyze the spatiotemporal expression of genes, and placing genes in regulatory cascades by analysis of genetic mutants and/or embryos injected with morpholinos (commonly termed as morphants) [5, 6].

Specifically for hematopoiesis, zebrafish blood contains cells of all hematopoietic lineages [7-11] and orthologs of most transcription factors involved in mammalian hematopoiesis have been identified indicating evolutionarily conserved pathways of regulation [12-15]. Initial validation of the use of zebrafish for hematopoiesis research came from the forward genetic screens. In 1996, two large-scale chemical mutagenesis screens were performed to identify mutants with a variety of phenotypes $[16,17]$. Of these, characterization of 46 mutants with blood phenotypes by allelic complementation suggested roles for at least 26 genes in hematopoiesis $[18,19]$. Subsequent efforts by several groups identified the underlying genetic defects in many of these mutants by positional cloning or candidate gene approaches. In addition to identifying the genes previously known to have a role in hematopoiesis (e.g., gatal, sptb, and, alas2), these mutants also uncovered novel genes with roles in hematopoiesis, (e.g., slc25a37, slc40a1, and glrx5) [2025]. Subsequent forward genetic screens focusing on mutants affecting specific hematopoietic lineages have identified additional conserved pathways of regulation between zebrafish and mammals [26-28].

This led to a surge of activity in zebrafish research laboratories, developing a variety of tools for thorough 
analysis of hematopoiesis. Lineage-specific transgenic lines were generated using promoters of a variety of hematopoietic genes driving fluorescent markers (reviewed in [29, 30] and listed in Table 1), allowing for visual observations of hematopoietic lineages in real-time during development. Advances in imaging combined with the ability to perform lineage tracing made it possible to follow the fate of specifically marked cells during development in a live vertebrate animal model $[31,32]$. Sorting of hematopoietic cells by fluorescence-activated cell sorting (FACS), in vitro culturing using zebrafish-specific cytokines and kidney stromal cells, and the ability to perform transplantation have facilitated characterization of hematopoietic potential of different mutants [33-37].

While forward screens are biased by the phenotype being screened, mutants in any specific gene can be generated using reverse genetic approaches. This has been made possible in zebrafish in the last decade by TILLING (Targeting-Induced Local Lesions IN Genomes) [55, 60], and more recently by targeted mutagenesis using zinc-finger and transcriptionactivator-like-effector nucleases (i.e. ZFNs and TALENs) [61-64]. Furthermore, effects of gene dosage can be analyzed by injecting suboptimal doses of antisense morpholinos or studying hypomorphic alleles generated by TILLING. In this review, we discuss how the technical advances and genomic tools discussed above went hand-in-hand with the elucidation of genetic controls of hematopoiesis in zebrafish.

\section{Ontogeny of Vertebrate Hematopoiesis}

In mammals, hematopoiesis occurs in successive but overlapping waves that occur at distinct anatomical locations [65]. Overall, the hematopoietic process is distinguished into primitive and definitive hematopoiesis based on the type of blood cells generated. Primitive hematopoiesis is transient in nature and produces unipotent blood cells that arise directly from the mesoderm. Definitive hematopoiesis produces multipotent blood cells that give rise to multiple different lineages through cellular intermediates and support blood cell development throughout the life of the organism. Here, we have summarized the overall process of mammalian hematopoiesis based on the studies using mouse models.

During embryogenesis, primitive hematopoiesis occurs in two distinct waves in the extraembryonic yolk sac blood islands, producing primitive macrophages and primitive erythrocytes, respectively, thus providing the developing embryos with oxygen and their first line of defense against pathogens [66]. There is some support for the presence of additional lineages, particularly megakaryocytes, during primitive hematopoiesis [67].

Definitive hematopoiesis also occurs in two distinct waves. The first wave of definitive hematopoiesis produces a transient population of cells, termed erythroid-myeloid progenitors (EMPs) in the yolk sac and fetal liver [68, 69]. The second wave of definitive hematopoiesis produces hematopoietic stem cells (HSCs) from the hemogenic endothelium of the embryo that includes the aorta-gonadmesonephros (AGM) region of the embryo, yolk sac, and placenta $[65,70-72]$. HSCs from these sites migrate through circulation to fetal liver to support hematopoiesis during embryogenesis $[65,70,73]$. Recently, Chen and colleagues [74] demonstrated that EMPs and HSCs are derived from two different hemogenic endothelial populations. Unlike HSCs, EMPs lack the potential to give rise to lymphocytes.

The site of adult hematopoiesis, where HSCs undergo differentiation to generate lineage-committed progenitors that give rise to all the mature blood cell types and selfrenewal to maintain a constant supply of HSCs, is bone marrow [75]. The prevailing thinking, based on the current data, is that HSCs emerging from the hemogenic endothelial cells in the AGM region of the developing mouse embryo give rise to most (if not all) bone marrow hematopoietic cells $[73,76]$. The shifting sites of hematopoiesis are thought to provide specific microenvironment cues required for the specification, and migration of precursors for lineage commitment $[77,78]$.

Although the overall process of hematopoiesis is well defined, we have just begun to elucidate the exact nature of the molecular controls and lineage relationships using in vitro colony assays and animal models, particularly mice and zebrafish. The key questions revolved around the generation, migration, and differentiation of HSCs into lineage-committed progenitors and how these processes are regulated to maintain a critical balance required for proper functioning of the hematopoietic system.

2.1. Primitive Hematopoiesis in Zebrafish. In zebrafish, the first blood cells can be observed in circulation at around 26 hours post fertilization (hpf). However, based on the expression patterns of the genes involved in primitive hematopoiesis, it is clear that the primitive hematopoiesis starts at $\sim 11 \mathrm{hpf}$ in the lateral plate mesoderm (LPM) during somitogenesis. The erythroid precursors are observed as bilateral stripes in the posterior lateral mesoderm (PLM) that fuse along the midline to form the intermediate cell mass (ICM) located in the trunk dorsal to the yolk tube extension by 24 hpf $[29,75,77,79-81]$. Primitive myeloid progenitors initiate at the anterior lateral mesoderm (ALM) and differentiate into macrophages in the rostral blood island $[80,82]$. Thus, primitive hematopoiesis in zebrafish occurs in two waves, producing primitive macrophages and primitive erythrocytes, respectively. In addition, neutrophils and thrombocytes have also been detected during primitive hematopoiesis in zebrafish. However, the origin of neutrophils during primitive hematopoiesis is not clear, as two recent reports presented contradictory data on their origin from either primitive macrophage lineage [83] or primitive erythrocyte lineage [84] using fate-mapping techniques. Thus, primitive blood cells in zebrafish appear to have diverse lineages, similar to the mouse [67]. However, further studies are required to clearly define the lineage relationships between these cell types during primitive hematopoiesis.

2.2. Definitive Hematopoiesis in Zebrafish. The hallmark of definitive hematopoiesis is generation of multipotential HSCs that can undergo self-renewal and differentiation to 
TABLE 1: Lineage-specific mutant and transgenic lines for zebrafish hematopoiesis research.

\begin{tabular}{|c|c|c|c|c|c|}
\hline \multirow[b]{2}{*}{ Lineage } & \multirow[b]{2}{*}{ Marker } & \multicolumn{2}{|c|}{ Mutant lines } & \multicolumn{2}{|c|}{ Transgenic lines } \\
\hline & & $\begin{array}{l}\text { Mutant designation and } \\
\text { mutation type }\end{array}$ & References & Line designation & References \\
\hline \multirow[t]{2}{*}{ Hemangioblast } & $\mathrm{tal1} / \mathrm{scl}$ & t21384, K183X & {$[38]$} & $\begin{array}{l}\text { PAC-tall:GFP } \\
\text { 5.0tal1:EGFP }\end{array}$ & {$[39,40]$} \\
\hline & $\operatorname{lmo} 2$ & \multicolumn{2}{|l|}{ None } & $\begin{array}{l}\text { lmo2:EGFP } \\
\text { lmo2:DsRed }\end{array}$ & {$[41]$} \\
\hline EMPs & runxl & hg1, W84X & {$[42,43]$} & runx1P1:EGFP & {$[44]$} \\
\hline \multirow{3}{*}{ HSCs } & $\operatorname{runxl}$ & hg1, W84X & {$[42,43]$} & runx1P2:EGFP & {$[44]$} \\
\hline & $c m y b$ & $\begin{array}{c}\mathrm{t} 25217, \mathrm{I} 181 \mathrm{~N} \\
\text { hkz3, truncation in } \\
\text { transactivation domain }\end{array}$ & $\begin{array}{l}{[45]} \\
{[46]}\end{array}$ & cmyb:EGFP & $\begin{array}{c}\text { Developed by the } \\
\text { Zon lab, used in } \\
\text { [47] }\end{array}$ \\
\hline & $c d 41$ & None & & cd41:GFP & {$[33,34]$} \\
\hline Erythropoiesis & gatal & $\begin{array}{c}\text { m651 (vlad tepes), R339X } \\
\text { hg2, T301K }\end{array}$ & $\begin{array}{l}{[23]} \\
{[48]} \\
\end{array}$ & $\begin{array}{l}\text { gata1:GFP } \\
\text { gata1:DsRed }\end{array}$ & {$[37,49]$} \\
\hline Myelopoiesis: GMPs & spil/pu.1 & None & & $\begin{array}{c}\text { spi1:EGFP } \\
\text { zpu.1:EGFP } \\
\end{array}$ & {$[50,51]$} \\
\hline \multirow{3}{*}{$\begin{array}{l}\text { Myelopoiesis: Neutrophils, } \\
\text { Macrophages, Monocytes }\end{array}$} & $m p x$ & None & & mpx:GFP & {$[52]$} \\
\hline & $l y z$ & None & & $\begin{array}{l}\text { lyz:EGFP } \\
\text { lyz:DsRed }\end{array}$ & {$[53]$} \\
\hline & mpeg1 & None & & $\begin{array}{l}\text { mpeg1:EGFP } \\
\text { mpeg1:mCherry }\end{array}$ & {$[54]$} \\
\hline \multirow{3}{*}{ Lymphopoiesis } & rag1 & t26683, R797X & [55] & rag1:GFP & [56] \\
\hline & lck & None & & lck:EGFP & {$[57]$} \\
\hline & ikzfl/ikaros & $\mathrm{t} 24980, \mathrm{Q} 360 \mathrm{X}$ & [58] & ikzf1:GFP & [59] \\
\hline
\end{tabular}

produce cells of erythroid, myeloid, and lymphoid lineages. In zebrafish HSCs can be identified by their expression of runxl and cmyb as early as $26 \mathrm{hpf}$ in the ventral wall of the dorsal aorta and hence this region of the embryo is referred to as the AGM [13, 29]. Two recent studies have unequivocally demonstrated the origin of HSCs from the hemogenic endothelium lining the ventral wall of the dorsal aorta using time lapse imaging and lineage tracing in double transgenic lines marking HSCs and endothelial cells with different fluorescent markers $[47,85]$. A novel process of cell transition, termed endothelial hematopoietic transition (EHT), appeared to be involved in the production of HSCs from hemogenic endothelium [85]. Similar to the mouse, a transient multipotent progenitor population of EMPs supports definitive hematopoiesis during embryogenesis and these EMPs originate in the posterior blood island (PBI) of zebrafish [86].

The sites of adult hematopoiesis in zebrafish are kidney marrow (analogous to the mammalian bone marrow) and thymus (for T cells) [13, 29, 87]. Up until recently, a site analogous to mammalian fetal liver was not recognized in the zebrafish. Therefore, HSCs from AGM were presumed to support embryonic definitive hematopoiesis and migrate to thymus and kidney for adult definitive hematopoiesis. However, two independent studies demonstrated the existence of an intermediate site of hematopoiesis posterior to the yolk tube extension, termed caudal hematopoietic tissue (CHT), using imaging and cell tracing techniques $[88,89]$. It was proposed that the function of $\mathrm{CHT}$ is analogous to that of the fetal liver in mammals for supporting definitive hematopoiesis during embryogenesis. By tracing the generation and migration of HSCs using cd41:GFPlow cells, Kissa and colleagues [90] validated the migratory route of HSCs as being AGM to CHT and then to thymus and pronephros. Recently, Hess and Boehm [91] elegantly imaged the process of thymopoiesis in real time in zebrafish using triple transgenic lines and their data suggested that AGM is a major source of thymus-settling lymphoid progenitors compared to CHT.

Thus, based on the current status of our understanding, definitive hematopoiesis in zebrafish occurs in two waves: first wave produces transient EMPs in the PBI region and second wave produces HSCs in the AGM region that migrate to CHT to support larval definitive hematopoiesis and to thymus and kidney marrow to support adult definitive hematopoiesis. It is not clear if the migration of HSCs from AGM to kidney and thymus is via CHT only or also occurs directly as was previously assumed.

\section{Elucidation of Genetic Controls of Hematopoiesis in Zebrafish}

Despite the spatial and temporal differences during hematopoiesis between zebrafish and mammals as discussed above, the overall process is highly conserved producing the same effective repertoire of hematopoietic cells. It begins from a cell, termed hemangioblast, that serves as a common 
precursor for hematopoiesis and vasculogenesis [92, 93]. A complex network of regulatory signals is involved in the specification and lineage commitment of precursors during primitive and definitive hematopoiesis in mammals. These include homeobox, notch, vegf, and wnt signaling pathways as well as specific transcription factors, such as Tall ( $\mathrm{Scl})$, Lmo2, Gata1, Cmyb, Runx1, Spil (Pu.1), and Ikzf1 (Ikaros), which are shown to function in a hierarchical manner [5, 94-99]. The importance of proper functioning of these transcription factors is evident from the preponderance of mutations and genomic rearrangements disrupting their activity detected in several blood disorders, particularly leukemias and lymphomas [100-106].

Animal models, where level of gene activity can be manipulated, have played a critical role in advancing our understanding of the genetic controls of hematopoiesis. However, knockout mice are embryonic lethal at mid-tolate gestation for Tal1, Lmo2, Gata1, Sfpil (Pu.1), Myb, and Runx1, thus precluding the examination of their roles in later stages of hematopoiesis [107-112]. Conditional knockout is a useful tool to determine the function of these genes later in life; however, it has been difficult to use this technology to study the initiating events of a lineage, especially for the HSCs, since appropriate promoters to drive Cre recombinase expression may not be available. Zebrafish provide an advantage over mouse models due to their ability to survive without blood for several days and are, therefore, a suitable model organism for investigating the effects of loss of function of genes that cause embryonic lethality in mice due to the hematopoietic defects. Here, we discuss the contributions of zebrafish mutants, morphants, and transgenic lines to our understanding of the regulatory cascade controlling the hematopoiesis process (Table 1 lists the lineage-specific transgenic lines and genetic mutants in transcription factors involved in regulation of hematopoiesis). The common theme in the studies reviewed below is utilization of the unique features of zebrafish embryos and available tools for analysis of the disruptions to the gene activity in an effort to understand the overall process.

3.1. Genes Involved at the Hemangioblast Level: tal1 and lmo2. Based on their expression in both hematopoietic and endothelial cells, and the phenotypes of loss of function animal models, the T-cell acute lymphocytic leukemia 1 (TAL1) and the LIM domain only 2 (LMO2) genes are both believed to function at the hemangioblast level $[12,113]$. Both genes were identified from translocations occurring in T-cell acute lymphoblastic leukemia, TAL1 from translocation $\mathrm{t}(1 ; 14)$ and $L M O 2$ from translocation $t(11 ; 14)[102,104]$. TAL1 is a basic helix-loop-helix (bHLH) transcription factor where the bHLH domain is involved in DNA binding as part of a multiprotein complex that includes LMO2 as a bridging protein. LMO2 belongs to the LMO family of zinc-finger proteins that are characterized by 2 LIM domains, each composed of 2 zinc fingers [104]. Knockout mice for Tall and Lmo2 died in utero by embryonic days 9.5-10.5 (E9.5-10.5) due to lack of embryonic erythropoiesis [108, 112]. Thus, their roles during definitive and adult hematopoiesis were investigated by in vitro colony assays, chimeric mice, and/or conditional knockout mice $[114,115]$. Failure to produce any myeloid colonies in vitro from Tal1 $^{-/-}$yolk sac cells indicated a block at the EMP level [108]. Using conditional knockout mice, Hall and colleagues $[114,116]$ demonstrated that adult hematopoiesis can occur independent of Tall function with minor defects in erythropoiesis and megakaryopoiesis. On the other hand, Lmo2 was shown to be absolutely necessary for adult hematopoiesis based on the analysis of chimeric mice derived from $L m o 2^{-/-}$embryonic stem cells [115].

In zebrafish, tal1 is expressed in the ALM and PLM from $\sim 11 \mathrm{hpf}$ and in the posterior ICM at $26 \mathrm{hpf}$, validating its role in primitive hematopoiesis $[39,117,118]$. First direct proof for the exact site of HSC initiation between the dorsal aorta and the posterior cardinal vein being analogous to AGM in zebrafish came from the examination of $\mathrm{Tg}(\mathrm{tal} 1-\mathrm{PAC}$ GFP) embryos by time lapse imaging [40]. Loss-of-function analyses for tall have been performed using morpholinos and a genetic truncation mutation, $\mathrm{K} 183 \mathrm{X}$, which deletes the bHLH domain [38, 119-121]. Homozygous mutant embryos $\left(\right.$ tal1 $\left.^{\mathrm{K} 183 \mathrm{X} / \mathrm{K} 183 \mathrm{X}}\right)$ exhibited lack of expression of markers of both primitive and definitive lineages and also lacked visible circulation at $26 \mathrm{hpf}$ [38]. These studies not only confirmed the role of Tall during primitive hematopoiesis, but also provided direct evidence for the role of Tall in the initiation of definitive hematopoiesis. However, mutant embryos died due to pericardial edema and defects in heart morphogenesis and could not be studied for the role of Tall in transition of embryonic to adult stages of definitive hematopoiesis.

In zebrafish, lmo2 expression in the ALM and PLM is detected about 20 minutes after the tall expression and phenotype of $1 m o 2$ morphants is very similar to the tall morphants, supporting their roles as part of the multiprotein complex during hemangioblast development [41, 122]. To date, no genetic mutants have been reported for $1 m o 2$. Overall, zebrafish studies have confirmed the strict requirements for Tall and Lmo2 in initiation of both primitive and definitive hematopoiesis.

3.2. Genes Involved at the HSC Level: runx1 and cmyb. The onset of definitive hematopoiesis in the AGM is marked by the specification of HSCs, which support hematopoiesis throughout the life of a vertebrate. runx 1 and $c m y b$ have been used interchangeably as the earliest markers of definitive hematopoiesis due to their expression in the AGM during HSCs specification $[12,123]$. However, we have just begun to elucidate their precise roles in HSCs specification, migration to the sites of larval and adult hematopoiesis, and differentiation into erythroid, myeloid, and lymphoid lineages.

RUNX1 belongs to a family of genes ( 3 members in mammals and 4 in zebrafish) that encode for the alpha subunits of a heterodimeric complex that binds DNA through the highly conserved runt domain. A single gene, $C B F B$, encodes for the beta subunit, which does not bind to DNA by itself but increases the affinity of alpha subunits to bind to DNA after heterodimerization through their runt domains [124]. Promoters of many hematopoietic genes, for example, SPI1 and GATA1, contain RUNX1 DNA binding sites [125-127]. RUNX1 was first identified in the $\mathrm{t}(8 ; 21)$ translocation frequently observed in acute myeloid leukemias and its 
dimerization partner, $C B F B$, is also frequently involved in genomic rearrangements associated with leukemia $[100,128$, 129]. Furthermore, mutations affecting the level of RUNX1 activity leading to loss of function, dominant negative gain of function, and/or overexpression are associated with other blood disorders such as familial platelet disorder with predisposition to acute myeloid leukemia and myelodysplastic syndrome, suggesting that the process of hematopoiesis is very sensitive to the level of RUNX1 activity [130-132].

Studies using knockout mouse models demonstrated that Runx1 is essential for the initiation of HSCs generation during definitive hematopoiesis as the mutant mice failed to develop fetal liver hematopoiesis and died in utero at E12.5 [111]. Conditional knockout mice were able to develop all lineages but showed defects in megakaryocyte maturation and differentiation of $\mathrm{B}$ and $\mathrm{T}$ cells $[133,134]$. Recent elegant fate mapping experiments in mouse embryos by Chen and colleagues demonstrated that Runx1 is required for the emergence of HSCs from the hemogenic endothelium [135]. Taken together, these data suggest a strict requirement of Runxl in the generation of HSCs to initiate definitive hematopoiesis and in further differentiation of certain lineages but not for the maintenance of HSCs if they are already produced (reviewed in [73]).

Zebrafish runx1 was identified based on its high similarity to the human RUNX1 in the runt homology domain $[123,136]$. Since then, several studies have validated the critical requirement of Runx 1 in the initiation of definitive hematopoiesis by morpholinos and characterization of a variety of hematopoietic mutants $[95,97,136,137]$. As these studies were performed prior to the recognition of CHT being the site of embryonic definitive hematopoiesis, they did not address Runx1 requirements in specification of EMPs and their transient nature precluded analysis of Runx1 requirements in adult hematopoiesis. None of the hematopoietic mutants from forward genetic screens mapped to the runx1 locus.

Therefore, our group performed TILLING to identify a truncation mutation, W84X, in the runt domain of runx 1 $[42,43]$. Homozygous mutant embryos displayed a complete lack of cells expressing markers of HSCs, definitive erythroid, myeloid, and lymphoid lineages in the CHT and thymus between 3-5 dpf [42, 43]. However, utilizing $\operatorname{Tg}(\operatorname{cd} 41$ :GFP) transgenic zebrafish, we were able to demonstrate that $\mathrm{cd} 41^{+}$ cells were formed in the runx $1^{W 84 X / W 84 X}$ fish in the AGM and $\mathrm{CHT}$ regions and migrate to the pronephros, even though they were negative for other HSC markers such as cmyb. Based on the analysis of circulating blood cells, the mutant fish displayed 3 distinct phases: first phase of normal circulating blood cells until around 6-8 dpf (presumably from normal primitive hematopoiesis), second phase of bloodless stage until around $20 \mathrm{dpf}$ leading to death in most larvae (defective larval definitive hematopoiesis), and astonishingly, $\sim 20 \%$ of the mutant larvae resumed blood circulation and grew as phenotypically normal adult fish with multilineage adult hematopoiesis [43]. We do not know exactly how these $20 \%$ runx 1 mutant larvae were rescued. One possibility is that the $\mathrm{cd} 41^{+}$cells observed in these embryos are hematopoiesis-committed or -primed mesoderm cells, which could restart hematopoiesis in permissive conditions, such as compensation by runx $2 a$, run $x 2 b$, and runx 3 genes or other genetic and/or epigenetic changes. Another scenario is that two waves of definitive hematopoiesis exist, one for larval and the other adult, while Runx 1 is only required for the larval stage. For both scenarios, most larvae died due to lack of circulating blood cells resulting from defective larval hematopoiesis. It is interesting to note that alternate runxl promoters are used during establishment of EMPs and HSCs (Table 1) as demonstrated recently by Lam and colleagues [44].

Similarly, MYB, a cellular homolog of the V-MYB protooncogene, is a critical transcription factor required for definitive hematopoiesis. A number of mouse models, including conventional and conditional knockouts as well as hypomorphic alleles, have been generated for functional analysis of Myb requirements during hematopoiesis, as discussed in a recent review by Greig and colleagues [109]. These studies have highlighted the key difference between Runx1 and $\mathrm{Myb}$ requirements during definitive hematopoiesis to be the generation of HSCs. Myb knockout mice displayed defects in erythroid and myeloid development and died in utero at E15.5, which is much later than the stage when HSCs are generated [109]. Furthermore, $M y b^{-/-}$ES cells were able to produce $\mathrm{T}$ cell progenitors in $\mathrm{Rag}^{-/-}$chimeric mice [138]. Thus, Myb deficiency causes a block in HSCs differentiation and lineage commitment rather than HSCs specification. Lieu and Reddy [139] demonstrated important contributions of Myb to self-renewal and differentiation of HSCs during adult hematopoiesis.

Recently, two groups reported characterization of loss of function mutants for cmyb in zebrafish: (1) allele t25127 with a missense mutation, I181N, affecting DNA binding domain and (2) allele hkz3, a splice site mutation leading to truncation of the transactivation domain. These mutants were identified from forward genetic screens for defects in thymopoiesis and lack of lysozyme C (lyz) expression, respectively $[45,46]$. Homozygous embryos for either mutation showed lack of definitive hematopoiesis but behaved differently with respect to survival. cmy $b^{I 181 N / I 181 N}$ mutant embryos displayed severe anemia and became bloodless by $20 \mathrm{dpf}$. Although the mutants survived for 2-3 months with stunted growth, there were no detectable hematopoietic cells by FACS or histology [45]. This is in contrast to our finding with $\operatorname{runx} 1^{\text {W84X/W84X }}$ mutants, thus suggesting differential requirements for runxl and cmyb activities during larval and adult hematopoiesis. On the other hand, most of the $\mathrm{cmyb}^{h k z 3}$ mutants (splice site mutation affecting the transactivation domain) died by $10 \mathrm{dpf}$. The authors did not explain the reason for this difference. We speculate that the husbandry differences between laboratories might be the reason for their differential survival in the absence of blood cells. Using time-lapse imaging of $c m y b^{h k z 3} / T g(c d 41: G F P)$ embryos and lineage tracing, Zhang and colleagues [46] demonstrated an important role for cmyb in the migration of HSCs from ventral wall of the dorsal aorta (VDA) to CHT, thereby proposing that migratory defects of HSCs maybe the cause of failure of definitive hematopoiesis in $c m y b$ deficient embryos. Thus, zebrafish models of cmyb deficiency have 
provided novel insights into its role in the migration of HSCs from AGM to CHT during definitive hematopoiesis.

3.3. Genes Involved at the Level of Erythropoiesis, Myelopoiesis, and Lymphopoiesis: gatal, spil, and ikzfl. Differentiation of HSCs during definitive hematopoiesis into lineagecommitted progenitors, which further differentiate into mature blood cells, is mediated by lineage-specific transcription factors [77]. Unlike HSCs, these lineage-committed progenitors lack the potential for self-renewal and thus require a constant supply of HSCs for their production $[87,140]$. The first series of lineage-committed multi-potent progenitors are termed common myeloid and common lymphoid progenitors (CMPs and CLPs). In mammals, CMPs further differentiate into megakaryocyte-erythroid progenitors (MEPs) that produce mature erythrocytes and platelets (erythropoiesis), and granulocyte/macrophage progenitors (GMPs) for the generation of mature myeloid cells (myelopoiesis). CLPs produce mature lymphoid lineage cells (lymphopoiesis). However, intermediate multilineage progenitors have not been identified in zebrafish yet, and all lineage relationships are speculative. Here, we have summarized the genetic controls of erythropoiesis, myelopoiesis, and lymphopoiesis in zebrafish.

Erythropoiesis involves differentiation of erythroidmyeloid progenitors into mature erythrocytes and thrombocytes. The master regulator of erythropoiesis is GATA1, a transcription factor belonging to the GATA family (6 members) that contains a conserved DNA binding domain consisting of two zinc fingers [140, 141]. Its consensus DNA binding site, WGATAR, is found in regulatory regions of most erythroid-specific genes [142]. Human mutations in GATA1 are associated with anemia, thrombocytopenia and acute megakaryoblastic leukemia in Down Syndrome patients [143]. Gata1 knockout mouse embryos die by E10.5 due to severe defects in erythropoiesis during primitive hematopoiesis, precluding assessment of its role in definitive hematopoiesis without generating conditional knockout mice $[107,144]$.

The zebrafish gatal gene was identified by crosshybridization with the zinc-finger region of Xenopus Gata1 [145]. Its expression is consistent with the sites of erythropoiesis during primitive hematopoiesis starting at 5somite stage [49]. Using positional cloning of one of the bloodless mutants, termed vlad tepes or $v l t^{m 651}$, identified in the 1996 large-scale forward screens, our group identified a truncation mutation, R339X, distal to the Cterminal zinc-finger domain in Gatal [23]. As expected, homozygous mutant embryos displayed defects in primitive erythropoiesis and lacked visible circulating blood cells at the onset of circulation. Evaluation of definitive hematopoiesis by WISH revealed similar defects in erythropoiesis but normal development of myeloid and lymphoid lineages, thus demonstrating the specific role of Gatal in generation of erythroid progenitor cells not only during primitive but also during definitive hematopoiesis $[23,48]$.

Myelopoiesis involves differentiation of erythroid-myeloid progenitors into differentiated macrophages/monocytes, mast cells, and granulocytes, including neutrophils and eosinophils $[9,80,82]$. The master regulator of myelopoiesis is SPI1 (previously known as PU.1), an oncogene originally identified as the site of genomic rearrangements by spleen focus-forming proviral insertion in erythroblastic tumors [103]. SPI1 belongs to the ETS family of transcription factors that bind DNA through a purine rich sequence, termed the PU box [146]. Sfpil knockout mice died around E18 due to multilineage defects, implicating additional roles of Sfpil in erythropoiesis and lymphopoiesis [110]. In vitro studies have demonstrated the importance of a negative cross-regulation of Gatal and Sfpil during erythroid and myeloid differentiation from CMPs [140]. Unlike mammals, the sites of erythropoiesis (PLM) and myelopoiesis (ALM) are separate in zebrafish during embryogenesis $[50,51]$. However, upregulation of myelopoiesis in gata1 morphants and ectopic expression of gatal in spil morphants proved that similar cross-regulation of these two transcription factors is critical for the proper commitments of erythroid and myeloid lineages in zebrafish [147, 148].

Lymphopoiesis involves differentiation of lymphoid progenitors into mature $\mathrm{T}$ and $\mathrm{B}$ cells that participate in a functional immune system of the organism [11]. Primary lymphoid organs for T-cell maturation in zebrafish are bilateral thymii, which are marked by expression of rag1, $i k z f 1$ and $l c k$ starting at $\sim 72 \mathrm{hpf}[56,57,59]$. Pancreas has been suggested as an intermediate site for the production of B cells [149] between $4 \mathrm{dpf}$ to $\sim 3$ weeks, at which point B cells become evident in the kidney. However, this remains to be verified, as no good transgenic markers of B cells currently exist to follow their development in real time. The master regulator of lymphopoiesis is the transcription factor IKZF1 (previously known as IKAROS) [150]. IKZF1 contains six zinc-fingers that are involved in DNA binding and protein-protein interactions [151]. By analysis of knockout mice, Wang and colleagues [152] demonstrated differential requirements of Ikzf1 for B- and T-cell differentiation during fetal and adult hematopoiesis. Ikzf1 null mice displayed complete blockage of differentiation of B cells during both fetal and postnatal stages. On the other hand, they displayed blockage of differentiation of $\mathrm{T}$ cells only during the fetal stage. Postnatal T-cell development recovered, albeit with deregulation of CD4 versus CD8 lineage commitment. Overall, their data suggested that Ikzf1 is essential for lymphopoiesis (both B and T cells) during fetal hematopoiesis, but it is dispensable for adult $\mathrm{T}$ cell development. Similar to the knockout mice, zebrafish with a truncation mutation, Q360X, in ikzf1 (ikzf $1^{t 24980}$ ), which removes the C-terminal two zinc fingers essential for protein-protein interactions, are adult viable [58]. Mutant fish displayed complete lack of lymphopoiesis during larval stage, and partial recovery after $14 \mathrm{dpf}$. Although the mutant fish survived and lived up to at least 17 months in nonsterile conditions, they displayed abnormal and inefficient lymphoid development. However, it is interesting to note that similar to our observations of two phases of definitive hematopoiesis in runxl mutants, zebrafish lacking Ikzf1 activity potentially demonstrated two phases of lymphoid development. In both cases, the larval phase is gene activity dependent while the adult phase develops to some extent despite the lack of gene activity. 


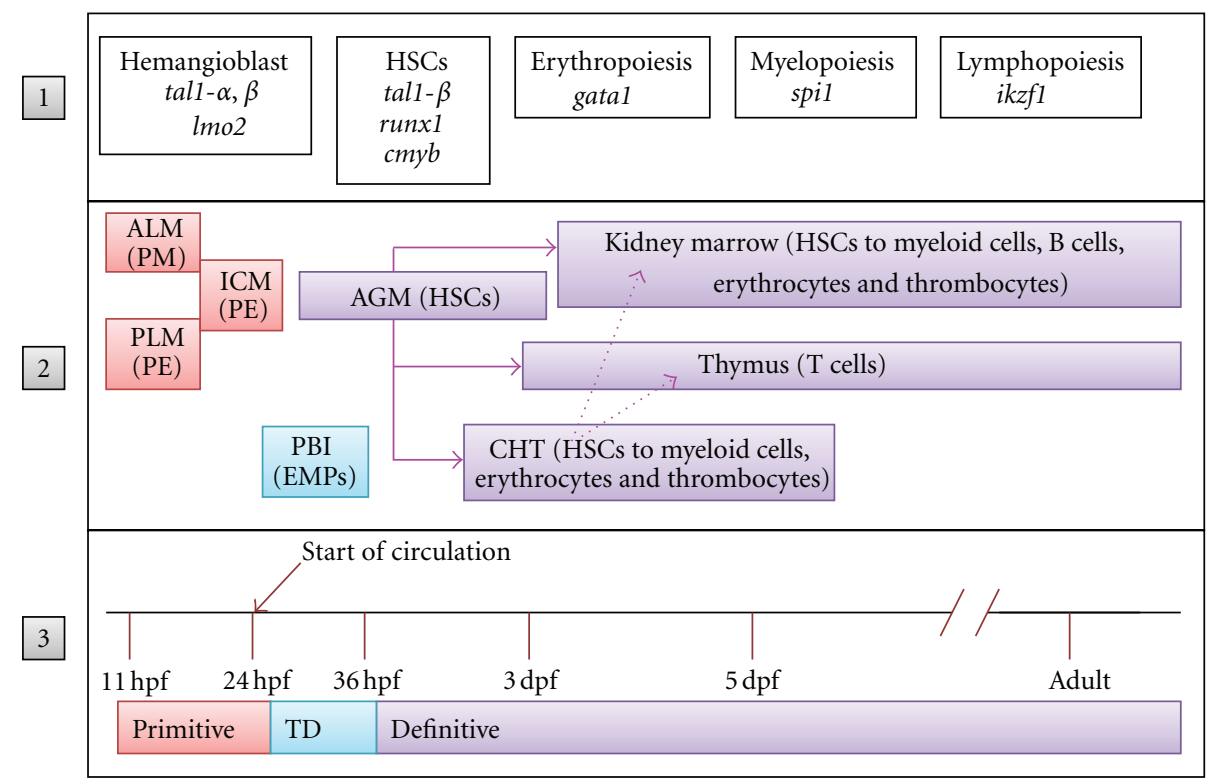

FIGURE 1: A schematic of overall view of zebrafish hematopoiesis with shifting sites, types of cells produced at each site, and genes involved, shown in 3 tiers as described below. Tier 1: lineage-specific transcription factors that control primitive and definitive hematopoiesis in zebrafish. Tier 2: the sites of action during each stage of hematopoiesis and the types of cells produced at each of the sites. The site boxes are color matched with waves of hematopoiesis and temporally placed according to the developmental stages in Tier 3. Tier 3: the time scale depicting the stage of development in hpf (hours postfertilization) and dpf (days postfertilization) and different waves of hematopoiesis. The abbreviations used are as follows: ALM: anterior lateral mesoderm, PLM: posterior lateral mesoderm, PBI: posterior blood island, AGM: aorta-gonad-mesonephros, CHT: caudal hematopoietic tissue, PM: primitive macrophages, PE: primitive erythrocytes, HSCs: hematopoietic stem cells, TD: transient definitive wave.

\section{Different Activity-Levels, Domains, and Isoforms of the Same Transcription Factors Are Required during Different Stages of Hematopoiesis}

Recent studies have demonstrated the need to address dosage requirements of transcription factors in the hematopoietic cascade as opposed to a simple on versus off situation [153156]. In zebrafish, it is relatively easy to manipulate gene dosage by careful tuning of morpholino doses and generation of hypomorphic alleles using TILLING. Therefore, differential requirements for some of the transcription factors either in terms of level of activity or different isoforms have been demonstrated recently in zebrafish, as discussed below.

4.1. Tall. As discussed previously, Tal1 plays critical roles during both primitive and definitive hematopoiesis. Using different doses of morpholinos to completely or partially abolish Tal1 activity, Juarez and colleagues [120] demonstrated differential requirements of tall expression for erythroid specification and maturation during primitive hematopoiesis. Their work showed that lower activity of Tal1 was sufficient for primitive erythroid specification but not their maturation. Furthermore, by complementation experiments with wild-type and DNA-binding mutant forms of Tall, they demonstrated differential requirements for the DNA-binding activity of Tall during erythroid specification and maturation. Their data suggested different mechanisms of target gene regulation during erythrocyte specification and maturation by Tall: direct binding to promoters of the target genes involved in erythroid maturation and indirect regulation through other protein complexes for genes involved in erythroid specification.

Further complexity to Tall requirements during primitive and definitive hematopoiesis became obvious from the analysis of its two isoforms: the full-length form termed Tal1- $\alpha$ and a shorter form lacking the first 146 amino acids, termed Tall- $\beta$. Using morpholinos to specifically target the $\alpha$ and $\beta$ forms, Qian and colleagues [157] demonstrated that both forms act redundantly in initiation of primitive hematopoiesis, while only the Tall- $\beta$ form is required for the specification of HSCs in the AGM to initiate definitive hematopoiesis. Ren and colleagues [158] examined the requirements of Tal1- $\alpha$ and Tal1- $\beta$ during angioblast and HSC specification, also demonstrating the requirement for Tal1- $\beta$ in HSC specification. Thus, zebrafish research has contributed significantly to our understanding of the regulation of different stages of hematopoiesis by Tall.

4.2. Gata1. Similar to Tal1, Gatal activity is crucial for erythropoiesis during both primitive and definitive hematopoiesis. Recently, we described a hypomorphic allele of Gatal due to a missense mutation, T301K, in its Cterminal zinc finger [48]. This mutation reduces DNA binding affinity and diminishes transactivation of target gene expression by Gata1 [48]. The gata1 ${ }^{\text {T301K/T301K }}$ fish had defective primitive erythropoiesis but normal definitive hematopoiesis. By combining the T301K allele with the 
Gata1 null allele of vlad tepes, we were able to generate an allelic series with different Gata1 activity levels, listed in the descending order: gata $^{+/+}$, gata $^{+/ T 301 K}$, gata $^{+/ v l t}$, gata $1^{T 301 K / T 301 K}$, gata $1^{T 301 K / v l t}$, gata $1^{\text {vlt/vlt }}$. Analysis of fish with these genotypes demonstrated that erythropoiesis during primitive hematopoiesis requires higher activity level of Gatal than erythropoiesis and thrombopoiesis during definitive hematopoiesis [48].

\section{Concluding Remarks}

Depicted in Figure 1 is a schematic of the overall view of zebrafish hematopoiesis emerging from these studies. It is clear from the above-mentioned studies that zebrafish has played a significant role in our understanding of the genetic controls of hematopoiesis, particularly the dosagespecific requirements during different stages. The viability to adulthood with multi-lineage hematopoiesis in runx1 knockout zebrafish clearly demonstrated that Runxl is dispensable for adult hematopoiesis. Similarly, Ikzf1 was found to be dispensable for adult lymphopoiesis. On the other hand, Cmyb was found to be essential for adult hematopoiesis, while dispensable for larval definitive stage. Genetic mutants need to be generated for spil to elucidate its exact role in maintaining proper balance between adult erythropoiesis and myelopoiesis.

Proper functioning of the genetic controls regulating hematopoiesis is crucial for normal development of all the blood lineages. Mutations in critical genes at many of the steps lead to leukemogenesis. Thus, adult viable mutant zebrafish would allow us to understand the process of leukemogenesis. Furthermore, the recent application of next generation sequencing technologies to a variety of leukemia samples have led to the identification of several new genes mutated in leukemias $[159,160]$. We anticipate that understanding their roles in normal hematopoiesis using the many advantages of the zebrafish model for hematopoiesis research would aid in therapeutic advances in the coming years.

\section{Acknowledgment}

This study was supported by the Intramural Research Program of the National Human Genome Research Institute, National Institutes of Health.

\section{References}

[1] J. Bradbury, "Small fish, big science," PLoS Biology, vol. 2, no. 5, article E148, 2004.

[2] C. Teh, S. Parinov, and V. Korzh, "New ways to admire zebrafish: progress in functional genomics research methodology," BioTechniques, vol. 38, no. 6, pp. 897-906, 2005.

[3] D. Wang, L. E. Jao, N. Zheng et al., "Efficient genomewide mutagenesis of zebrafish genes by retroviral insertions," Proceedings of the National Academy of Sciences of the United States of America, vol. 104, no. 30, pp. 12428-12433, 2007.

[4] B. R. Bill, A. M. Petzold, K. J. Clark, L. A. Schimmenti, and S. C. Ekker, "A primer for morpholino use in zebrafish," Zebrafish, vol. 6, no. 1, pp. 69-77, 2009.
[5] C. E. Burns, J. L. Galloway, A. C. H. Smith et al., "A genetic screen in zebrafish defines a hierarchical network of pathways required for hematopoietic stem cell emergence," Blood, vol. 113, no. 23, pp. 5776-5782, 2009.

[6] C. Thisse and B. Thisse, "High-resolution in situ hybridization to whole-mount zebrafish embryos," Nature Protocols, vol. 3, no. 1, pp. 59-69, 2008.

[7] C. E. Willett, A. Cortes, A. Zuasti, and A. G. Zapata, "Early hematopoiesis and developing lymphoid organs in the zebrafish," Developmental Dynamics, vol. 214, no. 4, pp. 323336, 1999.

[8] G. J. Lieschke, A. C. Oates, M. O. Crowhurst, A. C. Ward, and J. E. Layton, "Morphologic and functional characterization of granulocytes and macrophages in embryonic and adult zebrafish,” Blood, vol. 98, no. 10, pp. 3087-3096, 2001.

[9] J. T. Dobson, J. Seibert, E. M. Teh et al., "Carboxypeptidase A5 identifies a novel mast cell lineage in the zebrafish providing new insight into mast cell fate determination," Blood, vol. 112, no. 7, pp. 2969-2972, 2008.

[10] D. Carradice and G. J. Lieschke, "Zebrafish in hematology: sushi or science?” Blood, vol. 111, no. 7, pp. 3331-3342, 2008.

[11] S. A. Renshaw and N. S. Trede, "A model 450 million years in the making: zebrafish and vertebrate immunity," Disease Models and Mechanisms, vol. 5, no. 1, pp. 38-47, 2012.

[12] M. A. Thompson, D. G. Ransom, S. J. Pratt et al., "The cloche and spadetail genes differentially affect hematopoiesis and vasculogenesis," Developmental Biology, vol. 197, no. 2, pp. 248-269, 1998.

[13] J. L. O. de Jong and L. I. Zon, "Use of the zebrafish system to study primitive and definitive hematopoiesis," Annual Review of Genetics, vol. 39, pp. 481-501, 2005.

[14] F. Ellett and G. J. Lieschke, "Zebrafish as a model for vertebrate hematopoiesis," Current Opinion in Pharmacology, vol. 10, no. 5, pp. 563-570, 2010.

[15] L. Jingd and L. I. Zon, "Zebrafish as a model for normal and malignant hematopoiesis," Disease Models and Mechanisms, vol. 4, no. 4, pp. 433-438, 2011.

[16] W. Driever, L. Solnica-Krezel, A. F. Schier et al., "A genetic screen for mutations affecting embryogenesis in zebrafish," Development, vol. 123, pp. 37-46, 1996.

[17] P. Haffter, M. Granato, M. Brand et al., "The identification of genes with unique and essential functions in the development of the zebrafish, Danio rerio," Development, vol. 123, pp. 136, 1996.

[18] D. G. Ransom, P. Haffter, J. Odenthal et al., "Characterization of zebrafish mutants with defects in embryonic hematopoiesis," Development, vol. 123, pp. 311-319, 1996.

[19] B. M. Weinstein, A. F. Schier, S. Abdelilah et al., "Hematopoietic mutations in the zebrafish," Development, vol. 123, pp. 303-309, 1996.

[20] A. Brownlie, A. Donovan, S. J. Pratt et al., "Positional cloning of the zebrafish sauternes gene: a model for congenital sideroblastic anaemia," Nature Genetics, vol. 20, no. 3, pp. 244-250, 1998.

[21] A. Donovan, A. Brownlie, Y. Zhou et al., "Positional cloning of zebrafish ferroportin1 identifies a conserved vertebrate iron exporter," Nature, vol. 403, no. 6771, pp. 776-781, 2000.

[22] E. C. Liao, B. H. Paw, L. L. Peters et al., "Hereditary spherocytosis in zebrafish riesling illustrates evolution of erythroid $\beta$-spectrin structure, and function in red cell morphogenesis and membrane stability," Development, vol. 127, no. 23, pp. 5123-5132, 2000.

[23] S. E. Lyons, N. D. Lawson, L. Lei, P. E. Bennett, B. M. Weinstein, and P. Paul Liu, "A nonsense mutation in 
zebrafish gata1 causes the bloodless phenotype in vlad tepes," Proceedings of the National Academy of Sciences of the United States of America, vol. 99, no. 8, pp. 5454-5459, 2002.

[24] R. A. Wingert, J. L. Galloway, B. Barut et al., "Deficiency of glutaredoxin 5 reveals $\mathrm{Fe}-\mathrm{S}$ clusters are required for vertebrate haem synthesis," Nature, vol. 436, pp. 1035-1039, 2005.

[25] G. C. Shaw, J. J. Cope, L. Li et al., "Mitoferrin is essential for erythroid iron assimilation," Nature, vol. 440, no. 7080, pp. 96-100, 2006.

[26] B. M. Hogan, J. E. Layton, U. J. Pyati et al., "Specification of the primitive myeloid precursor pool requires signaling through Alk8 in zebrafish," Current Biology, vol. 16, no. 5, pp. 506-511, 2006.

[27] N. S. Trede, T. Ota, H. Kawasaki et al., "Zebrafish mutants with disrupted early T-cell and thymus development identified in early pressure screen," Developmental Dynamics, vol. 237, no. 9, pp. 2575-2584, 2008.

[28] M. C. Keightley, J. E. Layton, J. W. Hayman et al., "Mediator subunit 12 is required for neutrophil development in zebrafish," PloS ONE, vol. 6, no. 8, Article ID e23845, 2011.

[29] J. Y. Bertrand and D. Traver, "Hematopoietic cell development in the zebrafish embryo," Current Opinion in Hematology, vol. 16, no. 4, pp. 243-248, 2009.

[30] P. Zhang and F. Liu, "In vivo imaging of hematopoietic stem cell development in the zebrafish," Frontiers of Medicine in China, vol. 5, no. 3, pp. 239-247, 2011.

[31] C. Pardo-Martin, T. Y. Chang, B. K. Koo, C. L. Gilleland, S. C. Wasserman, and M. F. Yanik, "High-throughput in vivo vertebrate screening," Nature Methods, vol. 7, no. 8, pp. 634636, 2010.

[32] O. Renaud, P. Herbomel, and K. Kissa, "Studying cell behavior in whole zebrafish embryos by confocal live imaging: application to hematopoietic stem cells," Nature Protocols, vol. 6, no. 12, pp. 1897-1904, 2011.

[33] H. F. Lin, D. Traver, H. Zhu et al., "Analysis of thrombocyte development in CD41-GFP transgenic zebrafish," Blood, vol. 106, no. 12, pp. 3803-3810, 2005.

[34] D. Ma, J. Zhang, H. F. Lin, J. Italiano, and R. I. Handin, “The identification and characterization of zebrafish hematopoietic stem cells," Blood, vol. 118, no. 2, pp. 289-297, 2011.

[35] D. L. Stachura, J. R. Reyes, P. Bartunek, B. H. Paw, L. I. Zon, and D. Traver, "Zebrafish kidney stromal cell lines support multilineage hematopoiesis," Blood, vol. 114, no. 2, pp. 279289, 2009.

[36] D. L. Stachura, O. Svoboda, R. P. Lau et al., "Clonal analysis of hematopoietic progenitor cells in the zebrafish," Blood, vol. 118, no. 5, pp. 1274-1282, 2011.

[37] D. Traver, B. H. Paw, K. D. Poss, W. T. Penberthy, S. Lin, and L. I. Zon, "Transplantation and in vivo imaging of multilineage engraftment in zebrafish bloodless mutants," Nature Immunology, vol. 4, no. 12, pp. 1238-1246, 2003.

[38] J. Bussmann, J. Bakkers, and S. Schulte-Merker, "Early endocardial morphogenesis requires Scl/Tal1," PLoS Genetics, vol. 3, no. 8, article e140, 2007.

[39] H. Jin, J. Xu, F. Qian et al., “The $5^{\prime}$ zebrafish scl promoter targets transcription to the brain, spinal cord, and hematopoietic and endothelial progenitors," Developmental Dynamics, vol. 235, no. 1, pp. 60-67, 2006.

[40] X. Y. Zhang and A. R. F. Rodaway, "SCL-GFP transgenic zebrafish: in vivo imaging of blood and endothelial development and identification of the initial site of definitive hematopoiesis," Developmental Biology, vol. 307, no. 2, pp. 179-194, 2007.
[41] H. Zhu, D. Traver, A. J. Davidson et al., "Regulation of the 1 mo2 promoter during hematopoietic and vascular development in zebrafish," Developmental Biology, vol. 281, no. 2, pp. 256-269, 2005.

[42] H. Jin, R. Sood, J. Xu et al., "Definitive hematopoietic stem/progenitor cells manifest distinct differentiation output in the zebrafish VDA and PBI," Development, vol. 136, no. 4, pp. 647-654, 2009.

[43] R. Sood, M. A. English, C. L. Belele et al., "Development of multilineage adult hematopoiesis in the zebrafish with a runx1 truncation mutation," Blood, vol. 115, no. 14, pp. 2806-2809, 2010.

[44] E. Y. N. Lam, J. Y. M. Chau, M. L. Kalev-Zylinska et al., "Zebrafish runx1 promoter-EGFP transgenics mark discrete sites of definitive blood progenitors," Blood, vol. 113, no. 6, pp. 1241-1249, 2009.

[45] C. Soza-Ried, I. Hess, N. Netuschil, M. Schorpp, and T. Boehm, "Essential role of c-myb in definitive hematopoiesis is evolutionarily conserved," Proceedings of the National Academy of Sciences of the United States of America, vol. 107, no. 40, pp. 17304-17308, 2010.

[46] Y. Zhang, H. Jin, L. Li, F. X. F. Qin, and Z. Wen, "cMyb regulates hematopoietic stem/progenitor cell mobilization during zebrafish hematopoiesis," Blood, vol. 118, no. 15, pp. 4093-4101, 2011.

[47] J. Y. Bertrand, N. C. Chi, B. Santoso, S. Teng, D. Y. R. Stainier, and D. Traver, "Haematopoietic stem cells derive directly from aortic endothelium during development," Nature, vol. 464, no. 7285, pp. 108-111, 2010.

[48] C. L. Belele, M. A. English, J. Chahal et al., "Differential requirement for Gatal DNA binding and transactivation between primitive and definitive stages of hematopoiesis in zebrafish," Blood, vol. 114, no. 25, pp. 5162-5172, 2009.

[49] Q. Long, A. Meng, M. Wang, J. R. Jessen, M. J. Farrell, and S. Lin, "GATA-1 expression pattern can be recapitulated in living transgenic zebrafish using GFP reporter gene," Development, vol. 124, no. 20, pp. 4105-4111, 1997.

[50] K. Hsu, D. Traver, J. L. Kutok et al., "The pu.1 promoter drives myeloid gene expression in zebrafish," Blood, vol. 104, no. 5, pp. 1291-1297, 2004.

[51] A. C. Ward, D. O. McPhee, M. M. Condron et al., "The zebrafish spil promoter drives myeloid-specific expression in stable transgenic fish," Blood, vol. 102, no. 9, pp. 3238-3240, 2003.

[52] S. A. Renshaw, C. A. Loynes, D. M. I. Trushell, S. Elworthy, P. W. Ingham, and M. K. B. Whyte, "Atransgenic zebrafish model of neutrophilic inflammation," Blood, vol. 108, no. 13, pp. 3976-3978, 2006.

[53] C. Hall, M. Flores, T. Storm, K. Crosier, and P. Crosier, "The zebrafish lysozyme C promoter drives myeloid-specific expression in transgenic fish," BMC Developmental Biology, vol. 7, article 42, 2007.

[54] F. Ellett, L. Pase, J. W. Hayman, A. Andrianopoulos, and G. J. Lieschke, "mpeg1 promoter transgenes direct macrophagelineage expression in zebrafish," Blood, vol. 117, no. 4, pp. e49-e56, 2011.

[55] E. Wienholds, S. Schulte-Merker, B. Walderich, and R. H. A. Plasterk, "Target-selected inactivation of the zebrafish rag1 gene," Science, vol. 297, no. 5578, pp. 99-102, 2002.

[56] J. R. Jessen, C. E. Willett, and S. Lin, "Artificial chromosome transgenesis reveals long-distance negative regulation of rag1 in zebrafish," Nature Genetics, vol. 23, no. 1, pp. 15-16, 1999.

[57] D. M. Langenau, A. A. Ferrando, D. Traver et al., "In vivo tracking of T cell development, ablation, and engraftment in 
transgenic zebrafish," Proceedings of the National Academy of Sciences of the United States of America, vol. 101, no. 19, pp. 7369-7374, 2004.

[58] M. Schorpp, M. Bialecki, D. Diekhoff et al., "Conserved functions of Ikaros in vertebrate lymphocyte development: genetic evidence for distinct larval and adult phases of $\mathrm{T}$ cell development and two lineages of B cells in zebrafish," Journal of Immunology, vol. 177, no. 4, pp. 2463-2476, 2006.

[59] B. Bajoghli, N. Aghaallaei, I. Hess et al., "Evolution of genetic networks underlying the emergence of thymopoiesis in vertebrates," Cell, vol. 138, no. 1, pp. 186-197, 2009.

[60] R. Sood, M. A. English, M. Jones et al., "Methods for reverse genetic screening in zebrafish by resequencing and TILLING," Methods, vol. 39, no. 3, pp. 220-227, 2006.

[61] Y. Doyon, J. M. McCammon, J. C. Miller et al., "Heritable targeted gene disruption in zebrafish using designed zincfinger nucleases," Nature Biotechnology, vol. 26, no. 6, pp. 702-708, 2008.

[62] X. Meng, M. B. Noyes, L. J. Zhu, N. D. Lawson, and S. A. Wolfe, "Targeted gene inactivation in zebrafish using engineered zinc-finger nucleases," Nature Biotechnology, vol. 26, no. 6, pp. 695-701, 2008.

[63] P. Huang, A. Xiao, M. Zhou, Z. Zhu, S. Lin, and B. Zhang, "Heritable gene targeting in zebrafish using customized TALENs," Nature Biotechnology, vol. 29, no. 8, pp. 699-700, 2011.

[64] J. D. Sander, L. Cade, C. Khayter et al., "Targeted gene disruption in somatic zebrafish cells using engineered TALENs," Nature Biotechnology, vol. 29, no. 8, pp. 697-698, 2011.

[65] E. Dzierzak and N. A. Speck, "Of lineage and legacy: the development of mammalian hematopoietic stem cells," Nature Immunology, vol. 9, no. 2, pp. 129-136, 2008.

[66] J. Palis, J. Malik, K. E. McGrath, and P. D. Kingsley, "Primitive erythropoiesis in the mammalian embryo," International Journal of Developmental Biology, vol. 54, no. 6-7, pp. 10111018, 2010.

[67] J. Tober, A. Koniski, K. E. McGrath et al., "The megakaryocyte lineage originates from hemangioblast precursors and is an integral component both of primitive and of definitive hematopoiesis," Blood, vol. 109, no. 4, pp. 1433-1441, 2007.

[68] K. E. McGrath, J. M. Frame, G. J. Fromm et al., "A transient definitive erythroid lineage with unique regulation of the $\beta$ globin locus in the mammalian embryo," Blood, vol. 117, no. 17, pp. 4600-4608, 2011.

[69] J. Palis, R. J. Chan, A. Koniski, R. Patel, M. Starr, and M. C. Yoder, "Spatial and temporal emergence of high proliferative potential hematopoietic precursors during murine embryogenesis," Proceedings of the National Academy of Sciences of the United States of America, vol. 98, no. 8, pp. 4528-4533, 2001.

[70] H. K. A. Mikkola and S. H. Orkin, "The journey of developing hematopoietic stem cells," Development, vol. 133, no. 19, pp. 3733-3744, 2006.

[71] K. E. Rhodes, C. Gekas, Y. Wang et al., "The emergence of hematopoietic stem cells is initiated in the placental vasculature in the absence of circulation," Cell Stem Cell, vol. 2, no. 3, pp. 252-263, 2008.

[72] I. M. Samokhvalov, N. I. Samokhvalova, and S. I. Nishikawa, "Cell tracing shows the contribution of the yolk sac to adult haematopoiesis," Nature, vol. 446, no. 7139, pp. 1056-1061, 2007.

[73] G. Swiers, M. de Bruijn, and N. A. Speck, "Hematopoietic stem cell emergence in the conceptus and the role of Runx1," International Journal of Developmental Biology, vol. 54, no. 67, pp. 1151-1163, 2010.
[74] M. J. Chen, Y. Li, M. E. de Obaldia et al., "Erythroid/myeloid progenitors and hematopoietic stem cells originate from distinct populations of endothelial cells," Cell Stem Cell, vol. 9, no. 6, pp. 541-552, 2011.

[75] A. Medvinsky, S. Rybtsov, and S. Taoudi, "Embryonic origin of the adult hematopoietic system: advances and questions," Development, vol. 138, no. 6, pp. 1017-1031, 2011.

[76] A. C. Zovein, J. J. Hofmann, M. Lynch et al., "Fate tracing reveals the endothelial origin of hematopoietic stem cells," Cell Stem Cell, vol. 3, no. 6, pp. 625-636, 2008.

[77] S. H. Orkin and L. I. Zon, "Hematopoiesis: an evolving paradigm for stem cell biology," Cell, vol. 132, no. 4, pp. 631644, 2008.

[78] L. D. Wang and A. J. Wagers, "Dynamic niches in the origination and differentiation of haematopoietic stem cells," Nature Reviews Molecular Cell Biology, vol. 12, no. 10, pp. 643-655, 2011.

[79] J. Berman, K. Hsu, and A. T. Look, "Zebrafish as a model organism for blood diseases," British Journal of Haematology, vol. 123 , no. 4, pp. 568-576, 2003.

[80] J. N. Berman, J. P. Kanki, and A. T. Look, "Zebrafish as a model for myelopoiesis during embryogenesis," Experimental Hematology, vol. 33, no. 9, pp. 997-1006, 2005.

[81] A. J. Davidson and L. I. Zon, "The "definitive" (and "primitive") guide to zebrafish hematopoiesis," Oncogene, vol. 23, no. 43, pp. 7233-7246, 2004.

[82] M. O. Crowhurst, J. E. Layton, and G. J. Lieschke, "Developmental biology of zebrafish myeloid cells," International Journal of Developmental Biology, vol. 46, no. 4, pp. 483-492, 2002.

[83] D. Le Guyader, M. J. Redd, E. Colucci-Guyon et al., "Origins and unconventional behavior of neutrophils in developing zebrafish," Blood, vol. 111, no. 1, pp. 132-141, 2008.

[84] R. M. Warga, D. A. Kane, and R. K. Ho, "Fate mapping embryonic blood in zebrafish: multi- and unipotential lineages are segregated at gastrulation," Developmental Cell, vol. 16, no. 5, pp. 744-755, 2009.

[85] K. Kissa and P. Herbomel, "Blood stem cells emerge from aortic endothelium by a novel type of cell transition," Nature, vol. 464, no. 7285, pp. 112-115, 2010.

[86] J. Y. Bertrand, A. D. Kim, E. P. Violette, D. L. Stachura, J. L. Cisson, and D. Traver, "Definitive hematopoiesis initiates through a committed erythromyeloid progenitor in the zebrafish embryo," Development, vol. 134, no. 23, pp. 41474156, 2007.

[87] A. T. Chen and L. I. Zon, "Zebrafish blood stem cells," Journal of Cellular Biochemistry, vol. 108, no. 1, pp. 35-42, 2009.

[88] H. Jin, J. Xu, and Z. Wen, "Migratory path of definitive hematopoietic stem/progenitor cells during zebrafish development," Blood, vol. 109, no. 12, pp. 5208-5214, 2007.

[89] E. Murayama, K. Kissa, A. Zapata et al., "Tracing hematopoietic precursor migration to successive hematopoietic organs during zebrafish development," Immunity, vol. 25, no. 6, pp. 963-975, 2006.

[90] K. Kissa, E. Murayama, A. Zapata et al., "Live imaging of emerging hematopoietic stem cells and early thymus colonization," Blood, vol. 111, no. 3, pp. 1147-1156, 2008.

[91] I. Hess and T. Boehm, "Intravital imaging of thymopoiesis reveals dynamic lympho-epithelial interactions," Immunity, vol. 36, no. 2, pp. 298-309, 2012.

[92] J. W. Xiong, "Molecular and developmental biology of the hemangioblast," Developmental Dynamics, vol. 237, no. 5, pp. 1218-1231, 2008. 
[93] K. M. Vogeli, S. W. Jin, G. R. Martin, and D. Y. R. Stainier, "A common progenitor for haematopoietic and endothelial lineages in the zebrafish gastrula," Nature, vol. 443, no. 7109, pp. 337-339, 2006.

[94] B. Argiropoulos and R. K. Humphries, "Hox genes in hematopoiesis and leukemogenesis," Oncogene, vol. 26, no. 47, pp. 6766-6776, 2007.

[95] C. E. Burns, D. Traver, E. Mayhall, J. L. Shepard, and L. I. Zon, "Hematopoietic stem cell fate is established by the NotchRunx pathway," Genes and Development, vol. 19, no. 19, pp. 2331-2342, 2005.

[96] W. K. Clements, A. D. Kim, K. G. Ong, J. C. Moore, N. D. Lawson, and D. Traver, "A somitic Wnt16/Notch pathway specifies haematopoietic stem cells," Nature, vol. 474, no. 7350, pp. 220-224, 2011.

[97] M. Gering and R. Patient, "Hedgehog signaling is required for adult blood stem cell formation in zebrafish embryos," Developmental Cell, vol. 8, no. 3, pp. 389-400, 2005.

[98] D. Liang, J. R. Chang, A. J. Chin et al., "The role of vascular endothelial growth factor (VEGF) in vasculogenesis, angiogenesis, and hematopoiesis in zebrafish development," Mechanisms of Development, vol. 108, no. 1-2, pp. 29-43, 2001.

[99] L. Bugeon, H. B. Taylor, F. Progatzky et al., "The NOTCH pathway contributes to cell fate decision in myelopoiesis," Haematologica, vol. 96, no. 12, pp. 1753-1760, 2011.

[100] E. de Braekeleer, N. Douet-Guilbert, F. Morel, M. J. Le Bris, C. Férec, and M. de Braekeleer, "RUNX1 translocations and fusion genes in malignant hemopathies," Future Oncology, vol. 7, no. 1, pp. 77-91, 2011.

[101] N. L. DiFronzo, C. T. Leung, M. K. Mammel, K. Georgopoulos, B. J. Taylor, and Q. N. Pham, "Ikaros, a lymphoid-cellspecific transcription factor, contributes to the leukemogenic phenotype of a mink cell focus-inducing murine leukemia virus," Journal of Virology, vol. 76, no. 1, pp. 78-87, 2002.

[102] E. Lécuyer and T. Hoang, "SCL: from the origin of hematopoiesis to stem cells and leukemia," Experimental Hematology, vol. 32, no. 1, pp. 11-24, 2004.

[103] F. Moreau-Gachelin, A. Tavitian, and P. Tambourin, "Spi1 is a putative oncogene in virally induced murine erythroleukaemias," Nature, vol. 331, no. 6153, pp. 277-280, 1988.

[104] C. H. Nam and T. H. Rabbitts, "The role of LMO2 in development and in $\mathrm{T}$ Cell leukemia after chromosomal translocation or retroviral insertion," Molecular Therapy, vol. 13, no. 1, pp. 15-25, 2006.

[105] Y. Shima and I. Kitabayashi, "Deregulated transcription factors in leukemia," International Journal of Hematology, vol. 94, no. 2, pp. 134-141, 2011.

[106] R. Shimizu, J. D. Engel, and M. Yamamoto, "GATA1-related leukaemias," Nature Reviews Cancer, vol. 8, no. 4, pp. 279287, 2008.

[107] L. Pevny, M. C. Simon, E. Robertson et al., "Erythroid differentiation in chimaeric mice blocked by a targeted mutation in the gene for transcription factor GATA-1," Nature, vol. 349, no. 6306, pp. 257-260, 1991.

[108] R. A. Shivdasanl, E. L. Mayer, and S. H. Orkin, "Absence of blood formation in mice lacking the T-cell leukaemia oncoprotein tal-1/SCL," Nature, vol. 373, no. 6513, pp. 432434, 1995.

[109] K. T. Greig, S. Carotta, and S. L. Nutt, "Critical roles for c-Myb in hematopoietic progenitor cells," Seminars in Immunology, vol. 20, no. 4, pp. 247-256, 2008.
[110] E. W. Scott, M. C. Simon, J. Anastasi, and H. Singh, "Requirement of transcription factor PU.1 in the development of multiple hematopoietic lineages," Science, vol. 265, no. 5178, pp. 1573-1577, 1994.

[111] T. Okuda, J. van Deursen, S. W. Hiebert, G. Grosveld, and J. R. Downing, "AML1, the target of multiple chromosomal translocations in human leukemia, is essential for normal fetal liver hematopoiesis," Cell, vol. 84, no. 2, pp. 321-330, 1996.

[112] A. J. Warren, W. H. Colledge, M. B. L. Carlton, M. J. Evans, A. J. H. Smith, and T. H. Rabbitts, "The oncogenic cysteinerich LIM domain protein rbtn2 is essential for erythroid development," Cell, vol. 78, no. 1, pp. 45-57, 1994.

[113] S. L. D’Souza, A. G. Elefanty, and G. Keller, "SCL/Tal-1 is essential for hematopoietic commitment of the hemangioblast but not for its development," Blood, vol. 105, no. 10, pp. 3862-3870, 2005.

[114] M. A. Hall, D. J. Curtis, D. Metcalf et al., "The critical regulator of embryonic hematopoiesis, SCL, is vital in the adult for megakaryopoiesis, erythropoiesis, and lineage choice in CFU-S12," Proceedings of the National Academy of Sciences of the United States of America, vol. 100, no. 3, pp. 992-997, 2003.

[115] Y. Yamada, A. J. Warren, C. Dobson, A. Forster, R. Pannell, and T. H. Rabbitts, "The T cell leukemia LIM protein Lmo2 is necessary for adult mouse hematopoiesis," Proceedings of the National Academy of Sciences of the United States of America, vol. 95, no. 7, pp. 3890-3895, 1998.

[116] M. A. Hall, N. J. Slater, C. Glenn Begley et al., "Functional but abnormal adult erythropoiesis in the absence of the stem cell leukemia gene," Molecular and Cellular Biology, vol. 25, no. 15, pp. 6355-6362, 2005.

[117] M. Gering, A. R. F. Rodaway, B. Göttgens, R. K. Patient, and A. R. Green, "The SCL gene specifies haemangioblast development from early mesoderm," The EMBO Journal, vol. 17, no. 14, pp. 4029-4045, 1998.

[118] E. C. Liao, B. H. Paw, A. C. Oates, S. J. Pratt, J. H. Postlethwait, and L. I. Zon, "SCL/Tal-1 transcription factor acts downstream of cloche to specify hematopoietic and vascular progenitors in zebrafish," Genes and Development, vol. 12, no. 5, pp. 621-626, 1998.

[119] K. A. Dooley, A. J. Davidson, and L. I. Zon, "Zebrafish scl functions independently in hematopoietic and endothelial development," Developmental Biology, vol. 277, no. 2, pp. 522-536, 2005.

[120] M. A. Juarez, F. Su, S. Chun, M. J. Kiel, and S. E. Lyons, "Distinct roles for SCL in erythroid specification and maturation in zebrafish," The Journal of Biological Chemistry, vol. 280, no. 50, pp. 41636-41644, 2005.

[121] L. J. Patterson, M. Gering, and R. Patient, "Scl is required for dorsal aorta as well as blood formation in zebrafish embryos," Blood, vol. 105, no. 9, pp. 3502-3511, 2005.

[122] L. J. Patterson, M. Gering, C. E. Eckfeldt et al., "The transcription factors $\mathrm{Scl}$ and $\mathrm{Lmo} 2$ act together during development of the hemangioblast in zebrafish," Blood, vol. 109, no. 6, pp. 2389-2398, 2007.

[123] H. Kataoka, M. Ochi, K. I. Enomoto, and A. Yamaguchi, "Cloning and embryonic expression patterns of the zebrafish Runt domain genes, runxa and runxb," Mechanisms of Development, vol. 98, no. 1-2, pp. 139-143, 2000.

[124] M. Ichikawa, T. Asai, S. Chiba, M. Kurokawa, and S. Ogawa, "Runx1/AML-1 ranks as a master regulator of adult hematopoiesis," Cell Cycle, vol. 3, no. 6, pp. 722-724, 2004. 
[125] G. Huang, P. Zhang, H. Hirai et al., "PU.1 is a major downstream target of AML1 (RUNX1) in adult mouse hematopoiesis," Nature Genetics, vol. 40, pp. 51-60, 2008.

[126] J. Michaud, K. M. Simpson, R. Escher et al., "Integrative analysis of RUNX1 downstream pathways and target genes," BMC Genomics, vol. 9, article 363, 2008.

[127] M. R. Tijssen, A. Cvejic, A. Joshi et al., "Genome-wide analysis of simultaneous GATA1/2, RUNX1, FLI1, and SCL binding in megakaryocytes identifies hematopoietic regulators," Developmental Cell, vol. 20, no. 5, pp. 597-609, 2011.

[128] R. K. Hyde and P. P. Liu, "RUNX1 repression-independent mechanisms of leukemogenesis by fusion genes CBFBMYH11 and AML1-ETO (RUNX1-RUNX1T1)," Journal of Cellular Biochemistry, vol. 110, no. 5, pp. 1039-1045, 2010.

[129] N. A. Sangle and S. L. Perkins, "Core-binding factor acute myeloid leukemia," Archives of Pathology \& Laboratory Medicine, vol. 135, no. 11, pp. 1504-1509, 2011.

[130] J. K. Mangan and N. A. Speck, "RUNX1 mutations in clonal myeloid disorders: from conventional cytogenetics to next generation sequencing, a story 40 years in the making," Critical Reviews in Oncogenesis, vol. 16, no. 1-2, pp. 77-91, 2011.

[131] M. Osato, N. Asou, E. Abdalla et al., "Biallelic and heterozygous point mutations in the runt domain of the AML1/ PEBP $2 \alpha$ B gene associated with myeloblastic leukemias," Blood, vol. 93, no. 6, pp. 1817-1824, 1999.

[132] S. Schnittger, F. Dicker, W. Kern et al., "RUNX1 mutations are frequent in de novo AML with noncomplex karyotype and confer an unfavorable prognosis," Blood, vol. 117, no. 8, pp. 2348-2357, 2011.

[133] J. D. Growney, H. Shigematsu, Z. Li et al., "Loss of Runx1 perturbs adult hematopoiesis and is associated with a myeloproliferative phenotype," Blood, vol. 106, no. 2, pp. 494-504, 2005.

[134] M. Ichikawa, T. Asai, T. Saito et al., "AML-1 is required for megakaryocytic maturation and lymphocytic differentiation, but not for maintenance of hematopoietic stem cells in adult hematopoiesis," Nature Medicine, vol. 10, no. 3, pp. 299-304, 2004.

[135] M. J. Chen, T. Yokomizo, B. M. Zeigler, E. Dzierzak, and N. A. Speck, "Runx1 is required for the endothelial to haematopoietic cell transition but not thereafter," Nature, vol. 457, no. 7231, pp. 887-891, 2009.

[136] C. E. Burns, T. DeBlasio, Y. Zhou, J. Zhang, L. Zon, and S. D. Nimer, "Isolation and characterization of runxa and runxb, zebrafish members of the runt family of transcriptional regulators," Experimental Hematology, vol. 30, no. 12, pp. 1381-1389, 2002.

[137] M. L. Kalev-Zylinska, J. A. Horsfield, M. V. C. Flores et al., "Runx1 is required for zebrafish blood and vessel development and expression of a human RUNX-1-CBF2T1 transgene advances a model for studies of leukemogenesis," Development, vol. 129, no. 8, pp. 2015-2030, 2002.

[138] R. D. Allen III, T. P. Bender, and G. Siu, "c-Myb is essential for early T cell development," Genes and Development, vol. 13, no. 9, pp. 1073-1078, 1999.

[139] Y. K. Lieu and E. P. Reddy, "Conditional c-myb knockout in adult hematopoietic stem cells leads to loss of self-renewal due to impaired proliferation and accelerated differentiation," Proceedings of the National Academy of Sciences of the United States of America, vol. 106, no. 51, pp. 21689-21694, 2009.
[140] L. C. Doré and J. D. Crispino, "Transcription factor networks in erythroid cell and megakaryocyte development," Blood, vol. 118, no. 2, pp. 231-239, 2011.

[141] R. Ferreira, K. Ohneda, M. Yamamoto, and S. Philipsen, "GATA1 function, a paradigm for transcription factors in hematopoiesis," Molecular and Cellular Biology, vol. 25, no. 4, pp. 1215-1227, 2005.

[142] J. J. Welch, J. A. Watts, C. R. Vakoc et al., "Global regulation of erythroid gene expression by transcription factor GATA1," Blood, vol. 104, no. 10, pp. 3136-3147, 2004.

[143] W. A. Ciovacco, W. H. Raskind, and M. A. Kacena, "Human phenotypes associated with GATA-1 mutations," Gene, vol. 427, no. 1-2, pp. 1-6, 2008.

[144] Y. Fujiwara, C. P. Browne, K. Cunniff, S. C. Goff, and S. H. Orkin, "Arrested development of embryonic red cell precursors in mouse embryos lacking transcription factor GATA-1," Proceedings of the National Academy of Sciences of the United States of America, vol. 93, no. 22, pp. 12355-12358, 1996.

[145] H. W. Detrich III, M. W. Kieran, F. Y. Chan et al., "Intraembryonic hematopoietic cell migration during vertebrate development," Proceedings of the National Academy of Sciences of the United States of America, vol. 92, no. 23, pp. 10713-10717, 1995.

[146] P. Kastner and S. Chan, "PU.1: a crucial and versatile player in hematopoiesis and leukemia," International Journal of Biochemistry and Cell Biology, vol. 40, no. 1, pp. 22-27, 2008.

[147] J. L. Galloway, R. A. Wingert, C. Thisse, B. Thisse, and L. I. Zon, "Loss of Gata1 but not Gata2 converts erythropoiesis to myelopoiesis in zebrafish embryos," Developmental Cell, vol. 8, no. 1, pp. 109-116, 2005.

[148] J. Rhodes, A. Hagen, K. Hsu et al., "Interplay of pu.1 and Gatal determines myelo-erythroid progenitor cell fate in zebrafish," Developmental Cell, vol. 8, no. 1, pp. 97-108, 2005.

[149] N. Danilova and L. A. Steiner, "B cells develop in the zebrafish pancreas," Proceedings of the National Academy of Sciences of the United States of America, vol. 99, no. 21, pp. 13711-13716, 2002.

[150] K. Georgopoulos, "Haematopoietic cell-fate decisions, chromatin regulation and ikaros," Nature Reviews Immunology, vol. 2, no. 3, pp. 162-174, 2002.

[151] L. B. John and A. C. Ward, "The Ikaros gene family: transcriptional regulators of hematopoiesis and immunity," Molecular Immunology, vol. 48, no. 9-10, pp. 1272-1278, 2011.

[152] J. H. Wang, A. Nichogiannopoulou, L. Wu et al., "Selective defects in the development of the fetal and adult lymphoid system in mice with an Ikaros null mutation," Immunity, vol. 5, no. 6, pp. 537-549, 1996.

[153] N. Novershtern, A. Subramanian, L. N. Lawton et al., "Densely interconnected transcriptional circuits control cell states in human hematopoiesis," Cell, vol. 144, no. 2, pp. 296309, 2011.

[154] F. Rosenbauer, K. Wagner, J. L. Kutok et al., "Acute myeloid leukemia induced by graded reduction of a lineage-specific transcription factor, PU.1," Nature Genetics, vol. 36, no. 6, pp. 624-630, 2004.

[155] R. Shimizu, S. Takahashi, K. Ohneda, J. D. Engel, and M. Yamamoto, "In vivo requirements for GATA-1 functional domains during primitive and definitive erythropoiesis," The EMBO Journal, vol. 20, no. 18, pp. 5250-5260, 2001.

[156] H. Sakamoto, G. Dai, K. Tsujino et al., "Proper levels of cMyb are discretely defined at distinct steps of hematopoietic cell development," Blood, vol. 108, no. 3, pp. 896-903, 2006. 
[157] F. Qian, F. Zhen, J. Xu, M. Huang, W. Li, and Z. Wen, "Distinct functions for different scl isoforms in zebrafish primitive and definitive hematopoiesis," PLoS Biology, vol. 5, no. 5, article e132, 2007.

[158] X. Ren, G. A. Gomez, B. Zhang, and S. Lin, "Scl isoforms act downstream of etsrp to specify angioblasts and definitive hematopoietic stem cells," Blood, vol. 115, no. 26, pp. 53385346, 2010.

[159] T. J. Ley, E. R. Mardis, L. Ding et al., "DNA sequencing of a cytogenetically normal acute myeloid leukaemia genome," Nature, vol. 456, no. 7218, pp. 66-72, 2008.

[160] E. R. Mardis, L. Ding, D. J. Dooling et al., "Recurring mutations found by sequencing an acute myeloid leukemia genome," The New England Journal of Medicine, vol. 361, no. 11, pp. 1058-1066, 2009. 


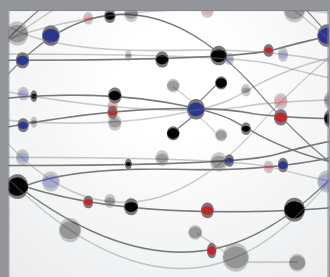

The Scientific World Journal
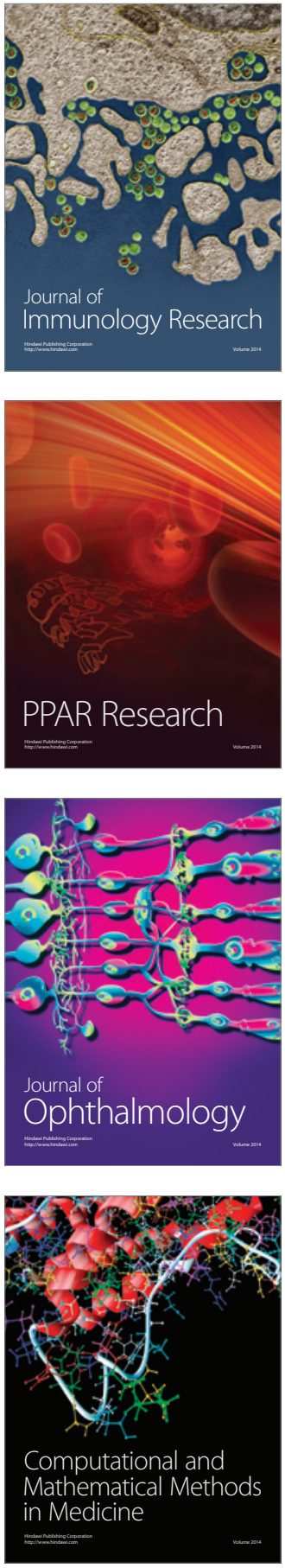

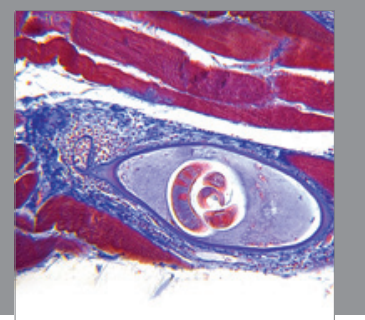

Gastroenterology

Research and Practice
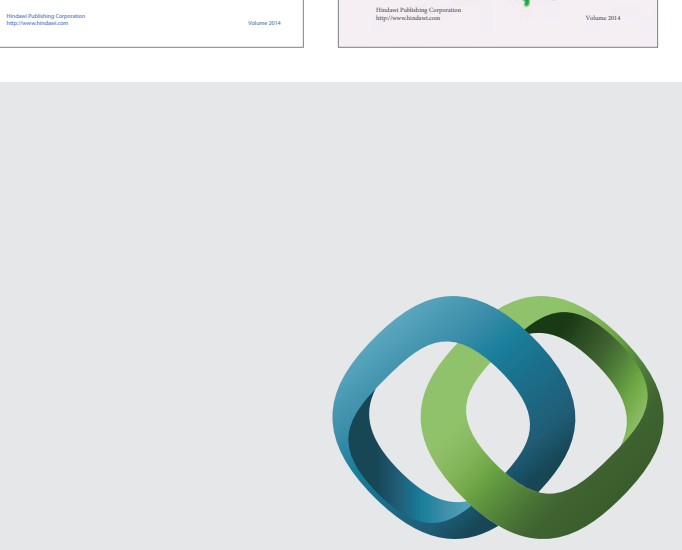

\section{Hindawi}

Submit your manuscripts at

http://www.hindawi.com
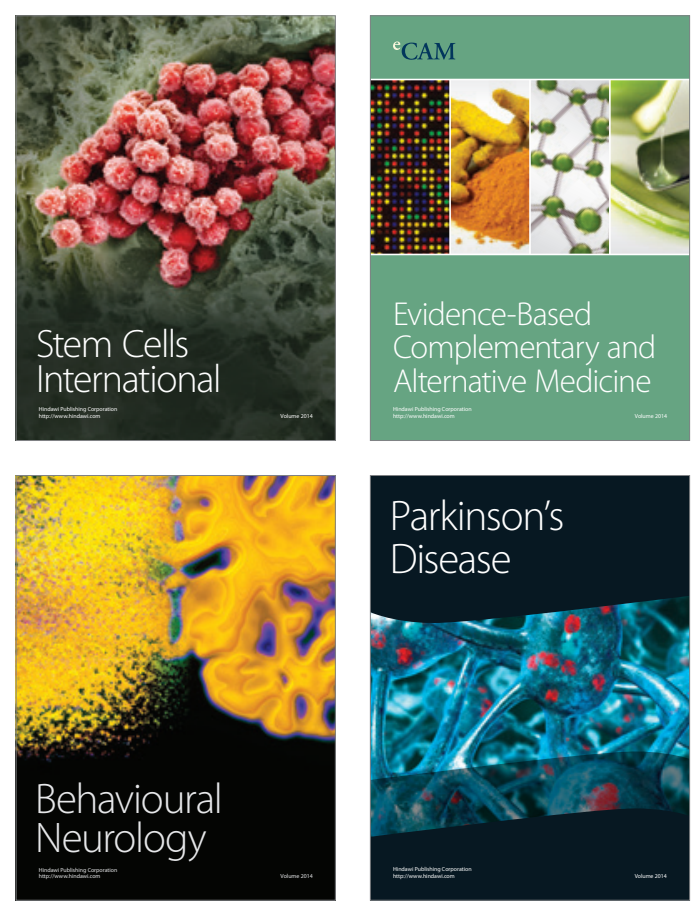

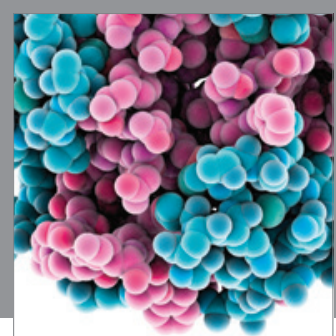

Journal of
Diabetes Research

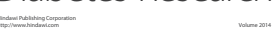

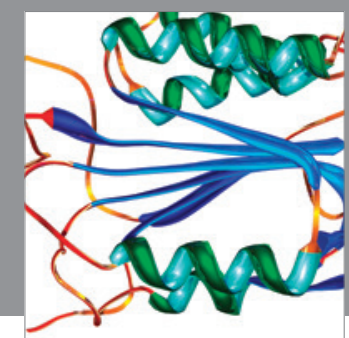

Disease Markers
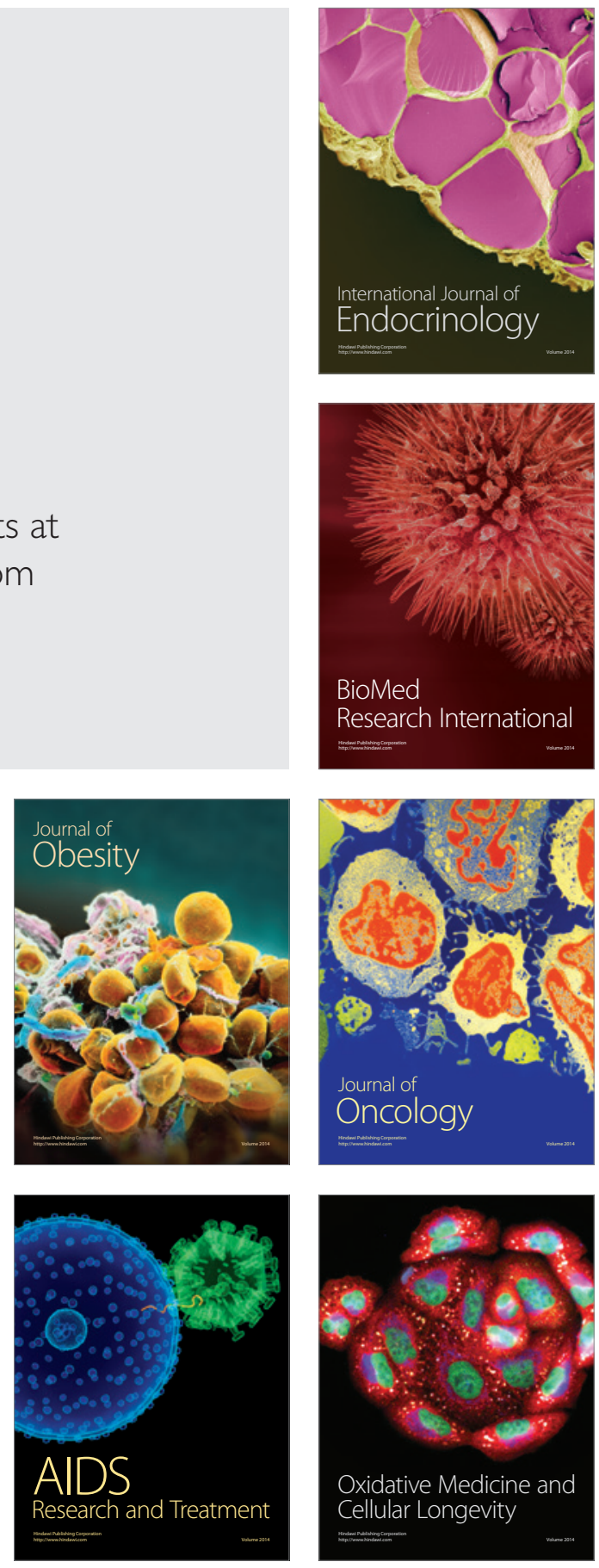